\title{
Use of computed tomographic scanning and aortography in the diagnosis of acute dissection of the thoracic aorta
}

John M Morgan, Paul J Oldershaw, Huon H Gray

\begin{abstract}
Before the introduction of computed tomographic (CT) scanning, aortography was the investigation of choice for acute aortic dissection. Between 1978 and 1982, 24 patients were referred to the Brompton Hospital with suspected acute thoracic aortic dissection; all had aortography with diagnosis confirmed at surgery $(n=12)$ or necropsy $(n=2)$ or supported by clinical outcome $(n=8)$. One patient in whom aortography was negative had type $B$ dissection at necropsy and another patient was lost to follow up. CT scanning became available in this unit in 1983 and between 1983 and 1987 was used as the only imaging investigation in 32 patients with suspected acute dissection of the thoracic aorta while in a further 22 patients aortography was used alone. Results were confirmed at surgery $(n=18)$, necropsy $(n=3)$, or supported by clinical outcome $(n=31)$. Two patients were lost to follow up. In an additional 16 patients both aortography and CT scanning were performed with concordant findings in 10. In six in whom the results were discordant, aortography was normal in three in whom subsequent CT scanning showed type $B$ dissection and CT scanning was normal in three patients in whom aortography showed type $A$ dissection.
\end{abstract}

Both CT scanning and aortography are reliable techniques for assessment of suspected acute dissection of the thoracic aorta. Both techniques misdiagnose occasionally and the frequency of misdiagnosis will be minimised by performing both investigations in patients where the level of clinical suspicion is high and the initial investigation negative. CT scanning tends to miss type A dissection and in view of the success of surgery in this condition this failing has the more serious clinical consequences.

Department of Cardiology, Brompton Hospital, London J M Morgan P J Oldershaw H H Gray

Correspondence to Dr John M Morgan, Royal Brompton and National Road, London SW3 6HP.

Acute dissection of the thoracic aorta is classified type A (affecting the ascending aorta) and type $B$ (not affecting the ascending aorta). ${ }^{1}$ Emergency surgical repair of type A dissection improves patient prognosis whereas immediate surgical intervention in type $B$, in the absence of complications, offers no choice for suspected acute dissection of the thoracic aorta ${ }^{4}$ but the advent of computed tomographic (CT) scanning now offers an alternative, non-invasive means of diagnosis. We report a 10 year experience of the clinical assessment and investigation of acute dissection of the thoracic aorta by these two techniques.

\section{Patients and methods}

Between 1978 and 198794 patients were referred to the Brompton Hospital with suspected acute dissection of the thoracic aorta. We reviewed the case records, investigations, and outcome in these patients; follow up data on all patients were obtained by communication with referring physicians and general practitioners or by review at the Brompton Hospital.

\section{STUDY DESIGN}

Patients are considered in two eras, before and after the introduction of CT scanning to this hospital, to assess the impact of CT scanning on the investigation of acute dissection. Before CT (1978-1982) 24 patients were referred and all underwent aortography. In the five years (1983-1987) after CT scanning became available 70 patients were referred with suspected acute dissection of the thoracic aorta. Thirty two patients had CT scanning, 22 had aortography, and 16 patients had both.

We accepted the result of either investigation as correct if it was confirmed by surgical or necropsy findings. But if only those patients with surgical or necropsy confirmation of diagnosis were included the study population would show a preponderance of those with type $\mathrm{A}$ aortic dissection because it is the policy of this unit to recommend urgent surgery to such patients because of the poor prognosis of type A dissection with medical management alone. We took a prolonged event-free survival as supporting accurate diagnosis in patients with dissection who were managed medically, or those with negative investigations, and we paid particular attention to the clinical circumstances of death in such patients to assess the likelihood that a type A dissection was missed. survival advantage. ${ }^{23}$ Until recently aortography was regarded as the investigation of

\section{Results}

AORTOGRAPHY 1978-1982

In 18 patients (eight female, 10 male; age 3582 , mean 68 years) aortography showed dissection of the thoracic aorta (table 1). Eight 
Table 1 Initial diagnosis, management, and confirmation of diagnosis in patients presenting with suspected acute dissection of the thoracic aorta $(A D A)$ between 1978 and 1982 and undergoing aortography

\begin{tabular}{|c|c|c|c|}
\hline $\begin{array}{l}\text { Patient } \\
\text { No }\end{array}$ & Result & Management & $\begin{array}{l}\text { Confirmation of } \\
\text { diagnosis }\end{array}$ \\
\hline $\begin{array}{r}1 \\
2 \\
3 \\
4 \\
5 \\
6 \\
7 \\
8 \\
9 \\
10 \\
11 \\
12 \\
13 \\
14 \\
15 \\
16 \\
17 \\
18 \\
19 \\
20 \\
21 \\
22 \\
23 \\
24\end{array}$ & $\begin{array}{l}\text { Type A } \\
\text { Type A } \\
\text { Type A } \\
\text { Type A } \\
\text { Type A } \\
\text { Type A } \\
\text { Type A } \\
\text { Type A } \\
\text { Type B } \\
\text { Type B } \\
\text { Type B } \\
\text { Type B } \\
\text { Type B } \\
\text { Type B } \\
\text { Type B } \\
\text { Type B } \\
\text { Type B } \\
\text { Type B } \\
\text { No ADA } \\
\text { No ADA } \\
\text { No ADA } \\
\text { No ADA } \\
\text { No ADA } \\
\text { No ADA }\end{array}$ & $\begin{array}{l}\text { Surgical } \\
\text { Surgical } \\
\text { Surgical } \\
\text { Surgical } \\
\text { Surgical } \\
\text { Surgical } \\
\text { Surgical } \\
\text { Surgical } \\
\text { Surgical } \\
\text { Surgical } \\
\text { Surgical } \\
\text { Surgical } \\
\text { Necropsy } \\
\text { Necropsy } \\
\text { Medical } \\
\text { Medical } \\
\text { Medical } \\
\text { Medical } \\
\text { Medical } \\
\text { Medical } \\
\text { Medical } \\
\text { Medical } \\
\text { Medical } \\
\text { Medical }\end{array}$ & $\begin{array}{l}\text { At surgery, type A } \\
\text { At surgery, type A } \\
\text { At surgery, type A } \\
\text { At surgery, type A } \\
\text { At surgery, type A } \\
\text { At surgery, type A } \\
\text { At surgery, type A } \\
\text { At surgery, type A } \\
\text { At surgery, type B } \\
\text { At surgery, type B } \\
\text { At surgery, type B } \\
\text { At surgery, type B } \\
\text { At necropsy, type B } \\
\text { At necropsy, type B } \\
\text { Suggested by FU } \\
\text { Suggested by FU } \\
\text { Suggested by FU } \\
\text { None: lost to FU } \\
\text { Suggested by FU } \\
\text { Suggested by FU - } \\
\text { Suggested by FU } \\
\text { Suggested by FU } \\
\text { Suggested by FU } \\
\text { Necropsy found type B }\end{array}$ \\
\hline
\end{tabular}

patients had type A dissections and all these were managed surgically. Ten patients had type $B$ dissections four of which were treated surgically and six medically. The diagnosis was confirmed in all 12 patients undergoing surgery. Of the six patients managed medically, one was lost to follow up, two had event-free survival of 66 and 77 months, and one died at five years (cause unknown). Two patients died within one month of diagnosis and in both of these the aortographic finding of type B dissection was confirmed at necropsy.

There were six patients (five male, one female; age 43-68, mean 59 years) with negative aortograms, three of whom had eventfree survival at 60-120 (mean 80) months follow up. One patient died five years later of carcinoma of the breast. Two others died within one month of aortography. One of these had been admitted for investigation having developed hemiplegia and dysphasia, the clinical suspicion of dissection resting on an absent brachial pulse, and died in coma three days after admission without subsequent necropsy. The other patient died 24 hours after admission and at necropsy was found to have type $B$ dissection. Thus this patient had a false negative aortogram.

\section{AORTOGRAPHY OR CT SCANNING OR}

BOTH 1983-1987

\section{CT scanning alone}

There were 12 patients (two female, 10 male; age 54-81, mean 68 years) in whom CT scanning showed acute dissection of the thoracic aorta (table 2). Six patients had type A dissections and all but one were managed surgically. Three patients had type $B$ dissections that required surgery because of complications and three patients had type B dissections that were managed medically. The diagnosis was confirmed in all patients undergoing surgery. Of the four patients managed medically, one elderly
Table 2 Initial diagnosis, management, and confirmation of diagnosis in patients presenting with suspected acute dissection of the thoracic aorta between 1983 and 1988 and undergoing CT scanning

\begin{tabular}{|c|c|c|c|}
\hline $\begin{array}{l}\text { Patient } \\
\text { No }\end{array}$ & Result & Management & $\begin{array}{l}\text { Confirmation of } \\
\text { diagnosis }\end{array}$ \\
\hline $\begin{array}{l}25 \\
26 \\
27 \\
28 \\
29 \\
30 \\
31 \\
32 \\
33 \\
34 \\
35 \\
36 \\
37 \\
38 \\
39 \\
40 \\
41 \\
42 \\
43 \\
44 \\
45 \\
46 \\
47 \\
48 \\
49 \\
50 \\
51 \\
52 \\
53 \\
54 \\
55 \\
56\end{array}$ & $\begin{array}{l}\text { Type A } \\
\text { Type A } \\
\text { Type A } \\
\text { Type A } \\
\text { Type A } \\
\text { Type A } \\
\text { Type B } \\
\text { Type B } \\
\text { Type B } \\
\text { Type B } \\
\text { Type B } \\
\text { Type B } \\
\text { No ADA } \\
\text { No ADA } \\
\text { No ADA } \\
\text { No ADA } \\
\text { No ADA } \\
\text { No ADA } \\
\text { No ADA } \\
\text { No ADA } \\
\text { No ADA } \\
\text { No ADA } \\
\text { No ADA } \\
\text { No ADA } \\
\text { No ADA } \\
\text { No ADA } \\
\text { No ADA } \\
\text { No ADA } \\
\text { No ADA } \\
\text { No ADA } \\
\text { No ADA } \\
\text { No ADA }\end{array}$ & $\begin{array}{l}\text { Surgical } \\
\text { Surgical } \\
\text { Surgical } \\
\text { Surgical } \\
\text { Surgical } \\
\text { Medical } \\
\text { Surgical } \\
\text { Surgical } \\
\text { Surgical } \\
\text { Medical } \\
\text { Medical } \\
\text { Medical } \\
\text { Medical } \\
\text { Medical } \\
\text { Medical } \\
\text { Medical } \\
\text { Medical } \\
\text { Medical } \\
\text { Medical } \\
\text { Medical } \\
\text { Medical } \\
\text { Medical } \\
\text { Medical } \\
\text { Medical } \\
\text { Medical } \\
\text { Medical } \\
\text { Medical } \\
\text { Medical } \\
\text { Medical } \\
\text { Medical } \\
\text { Medical } \\
\text { Medical }\end{array}$ & $\begin{array}{l}\text { At surgery, type A } \\
\text { At surgery, type A } \\
\text { At surgery, type A } \\
\text { At surgery, type A } \\
\text { At surgery, type A } \\
\text { No confirmation } \\
\text { At surgery, type B } \\
\text { At surgery, type B } \\
\text { At surgery, type B } \\
\text { Suggested by FU } \\
\text { Suggested by FU } \\
\text { Suggested by FU } \\
\text { Suggested by FU } \\
\text { Suggested by FU } \\
\text { Suggested by FU } \\
\text { Suggested by FU } \\
\text { Suggested by FU } \\
\text { Suggested by FU } \\
\text { Suggested by FU } \\
\text { Suggested by FU } \\
\text { Suggested by FU } \\
\text { Suggested by FU } \\
\text { Suggested by FU } \\
\text { Suggested by FU } \\
\text { Suggested by FU } \\
\text { Suggested by FU } \\
\text { Suggested by FU } \\
\text { Suggested by FU } \\
\text { Suggested by FU } \\
\text { Suggested by FU } \\
\text { Necropsy, no ADA } \\
\text { Surgery, no ADA }\end{array}$ \\
\hline
\end{tabular}

patient with a type A dissection was moribund on admission and died one hour later without surgery being attempted. Necropsy was not performed. The remaining three patients (type $B$ dissection) had event-free survival at a follow up of 19-48 (mean 30) months.

There were 20 patients ( 10 male, 10 female; age 50-79 (mean 63) years) with negative CT scans, of whom 15 had event-free survivals of 2-66 (mean 24) months (table 2). Five patients have died. Two patients aged 72 and 79 years died in old peoples' homes 15 months and 30 months after investigation and necropsies were not performed. A third patient died four months after investigation of myocardial infarction; this diagnosis and absence of dissection were confirmed at necropsy. A fourth patient died in hospital during aortic aneurysmectomy and no aortic dissection was found at necropsy. The final patient died five years after investigation and the cause of death is unknown.

\section{Aortography alone}

There were 14 patients (three female, 11 male; age 27-73, mean 62 years) in whom aortography showed dissection of the thoracic aorta (table 3). Eight patients had type A dissections and all these were managed surgically. Six patients had type B dissections two of which were managed surgically and four medically. The diagnosis was confirmed in all 10 patients undergoing surgery. Of the four patients managed medically, two were lost to follow up and one had event-free survival at 60 months follow up. One patient died of an unrelated myocardial infarction one year after investigation and necropsy confirmed an old type B dissection.

There were eight patients (seven male, one female; age 61-73, mean 68 years) with 
Table 3 Initial diagnosis, management, and confirmation of diagnosis in patients presenting with suspected acute dissection of the thoracic aorta between 1983 and 1988 and undergoing aortography

\begin{tabular}{|c|c|c|c|}
\hline $\begin{array}{l}\text { Patient } \\
\text { No }\end{array}$ & Result & Management & $\begin{array}{l}\text { Confirmation } \\
\text { of diagnosis }\end{array}$ \\
\hline $\begin{array}{l}57 \\
58 \\
59 \\
60 \\
61 \\
62 \\
63 \\
64 \\
65 \\
66 \\
67 \\
68 \\
69 \\
70 \\
71 \\
72 \\
73 \\
74 \\
75 \\
76 \\
77 \\
78\end{array}$ & $\begin{array}{l}\text { Type A } \\
\text { Type A } \\
\text { Type A } \\
\text { Type A } \\
\text { Type A } \\
\text { Type A } \\
\text { Type A } \\
\text { Type A } \\
\text { Type B } \\
\text { Type B } \\
\text { Type B } \\
\text { Type B } \\
\text { Type B } \\
\text { Type B } \\
\text { No ADA } \\
\text { No ADA } \\
\text { No ADA } \\
\text { No ADA } \\
\text { No ADA } \\
\text { No ADA } \\
\text { No ADA } \\
\text { No ADA }\end{array}$ & $\begin{array}{l}\text { Surgical } \\
\text { Surgical } \\
\text { Surgical } \\
\text { Surgical } \\
\text { Surgical } \\
\text { Surgical } \\
\text { Surgical } \\
\text { Surgical } \\
\text { Surgical } \\
\text { Surgical } \\
\text { Medical } \\
\text { Medical } \\
\text { Medical } \\
\text { Medical } \\
\text { Medical } \\
\text { Medical } \\
\text { Medical } \\
\text { Medical } \\
\text { Medical } \\
\text { Medical } \\
\text { Medical } \\
\text { Medical }\end{array}$ & $\begin{array}{l}\text { At surgery, type A } \\
\text { At surgery, type } \\
\text { At surgery, type } A \\
\text { At surgery, type A } \\
\text { At surgery, type A } \\
\text { At surgery, type A } \\
\text { At surgery, type A } \\
\text { At surgery, type A } \\
\text { At surgery, type B } \\
\text { At surgery, type B } \\
\text { Suggested by FU } \\
\text { Lost to FU } \\
\text { Lost to FU } \\
\text { Necropsy, type B } \\
\text { Suggested by FU } \\
\text { Suggested by FU } \\
\text { Suggested by FU } \\
\text { Suggested by FU } \\
\text { Suggested by FU } \\
\text { Suggested by FU } \\
\text { Suggested by FU } \\
\text { Suggested by FU }\end{array}$ \\
\hline
\end{tabular}

negative aortograms, seven of whom had eventfree survival of 20-51 (mean 38) months (table 3). One patient, however, died 24 months later of myocardial infarction, confirmed by a rise in cardiac enzymes and the electrocardiogram. There was no clinical suspicion of dissection but no necropsy was performed.

\section{CT SCANNING AND AORTOGRAPHY}

When the first investigation (either CT scanning or aortography) was negative or gave insufficient information for clinical management and there was strong clinical evidence of dissection, a second investigation (CT scanning or aortography) was always performed. A total of 16 patients ( 12 male, four female; age 55-73, mean 64 years) underwent both investigations for this reason (table 4).

Both aortography and CT scanning negative In eight patients, both investigations were negative and seven of these had event-free survival at follow up of 5-48 (mean 15) months. One was diagnosed as having a ventricular septal defect rather than dissection and died during surgical closure.

Table 4 Diagnosis, management, and confirmation of diagnosis in patients presenting with suspected acute dissection of the thoracic aorta between 1983 and 1988 and undergoing aortography and CT scanning

\begin{tabular}{lllll}
\hline Patient No & Aortography & CT & Management & Confirmation of diagnosis \\
\hline 79 & No ADA & No ADA & Medical & Suggested by FU \\
80 & No ADA & No ADA & Medical & Suggested by FU \\
81 & No ADA & No ADA & Medical & Suggested by FU \\
82 & No ADA & No ADA & Medical & Suggested by FU \\
83 & No ADA & No ADA & Medical & Suggested by FU \\
84 & No ADA & No ADA & Medical & Suggested by FU \\
85 & No ADA & No ADA & Medical & Suggested by FU \\
86 & No ADA & No ADA & Medical & Surgery, no ADA \\
87 & Type A & No ADA & Surgical & Surgery, type A \\
88 & Type A & No ADA & Surgical & Surgery, type A \\
89 & Type A & No ADA & Surgical & Surgery, type A \\
90 & Type B & Type B & Surgical & Surgery, type B \\
91 & No ADA & Type B & Medical & Necropsy, type B \\
92 & No ADA & Type B & Medical & Suggested by FU \\
93 & No ADA & Type B & Medical & Suggested by FU \\
94 & Type B & Type B & Medical & Suggested by FU \\
\hline
\end{tabular}

Aortography or CT scanning or both positive Eight patients had an abnormal CT scan or aortography. Four of these had CT scanning as the first investigation, with a negative result in three. There was a positive result in the fourth (type B dissection) but the CT scan gave insufficient information for further management. Aortography was therefore performed; it showed type A dissections in the three patients with negative CT scans, all of whom were referred for surgery (with confirmation of the diagnosis at operation). In the fourth patient aortography delineated the extent of the type B dissection. This patient was managed medically but later required surgery (when the diagnosis was confirmed) because of complications.

In four patients aortography was the first investigation and was negative in three. In the fourth patient aortography showed a type B dissection but further evidence that there was no type A dissection was considered necessary. CT scanning was therefore performed; it showed type B dissections in all. One patient, who was considered unfit for surgery despite clinical deterioration, died soon after admission, with necropsy confirmation of the diagnosis. The remaining three patients have had event-free survivals of 4-18 (mean 9) months.

In those patients in whom both CT scanning and aortography were required, the investigations were concordant in 10 patients and discordant in six. Aortography was negative in three patients in whom subsequent CT scanning showed type $B$ dissection. In three patients CT scanning was negative, but subsequent aortography showed type A dissections.

\section{Discussion}

Before CT scanning became available aortography was the investigation of choice for suspected acute dissection of the thoracic aorta. ${ }^{4}$ CT scanning is now available in most cardiac units in the United Kingdom and has been reported to be an effective alternative. ${ }^{56}$ Most of the studies using both these techniques in the investigation of aortic dissection have been small and this has limited their value. ${ }^{67}$ Oudberk et al reported a series of 26 patients undergoing CT scanning alone and found no misdiagnosis, ${ }^{8}$ whereas Vasile et al reported a misdiagnosis rate of $5.2 \%$ in a series of 137 patients. ${ }^{9}$ Streak artefact, difficulty in distinguishing aortic dissection from aortic aneurysm, absence of density difference between true and false lumens, and failure to manipulate window widths and levels were identified as major reasons for the errors in CT scanning. Aortography can also be erroneous as illustrated by Eagle et al who identified four false negative aortograms out of a series of 55 true negatives. ${ }^{10}$ Some argue that $\mathrm{CT}$ scanning is the best investigation for the assessment of acute thoracic aortic dissection ${ }^{11} 12$ while others argue that a negative CT scan does not remove the need for aortography. ${ }^{13}$

We sought to determine the accuracy of CT 
scanning and aortography in the investigation of patients referred with suspected acute dissection of the thoracic aorta and to determine their respective indications. It was not our intention to comment on the management of patients with proven dissection.

All 34 patients in our series who underwent surgery for acute thoracic aortic dissection had the preoperative diagnosis confirmed by surgery, and there were therefore no false positives in this group. Also there were no false positives in patients who died during the follow up period and in whom necropsy was performed $(n=4)$. To assess the possible frequency of false negative or erroneous results of CT scanning and aortography in patients whose management was medical (usually type B dissections) or those in whom no dissection was found, we looked for early deaths or suspicious clinical events during follow up. We accept that such an assessment must inevitably be imperfect because patients with an incorrect diagnosis may also have an event-free survival. The inclusion of any of these patients, were they known, would only increase the frequency of false negative or erroneous results. There were no suspicious events other than death and we therefore concentrated on those patients dying during follow up $(n=10)$ and tried to exclude dissection as contributing to the cause of death. This was often not possible but all cases in which the cause of death was not proven were reviewed.

In the era when only aortography was available (1978-1982) one patient died of unknown cause five years after being investigated and no further information was available. One patient was admitted for investigation of suspected dissection after having a cerebrovascular accident and died in coma. Aortography was negative but a necropsy was not performed and therefore we cannot exclude the presence of a dissection though a primary cerebral episode, rather than a neurological complication of dissection, seemed the most likely cause of death. Another patient died within one month of investigation and necropsy showed a type $B$ dissection that had not been noted on the aortogram. This was a false negative result. In this patient the clinical findings were strongly suggestive of dissection, and CT scanning had it been available might have resulted in the correct diagnosis being made.

After the introduction of CT scanning there was an increase in the number of patients referred with suspected acute dissection of the thoracic aorta ( 70 patients in the five years 1983-1987 compared with 24 patients between 1978 and 1982). This could represent a true rise in the incidence of aortic dissection in the referral population but we think this unlikely. Referral patterns change over the years and we cannot exclude the possibility that the number of referring physicians increased. It seems more likely, however, that two other factors were mostly responsible. First, it has become increasingly widely appreciated that the prognosis of patients with type A dissection can be improved by immediate surgery. Second, physicians may be more likely to refer patients for a non-invasive investigation such as CT scanning when the level of clinical suspicion is relatively low rather than subjecting them to aortography which has been regarded by some to be potentially dangerous. The non-invasive nature of CT scanning is in our opinion its greatest advantage. On the other hand, aortography offers the ability to assess any aortic regurgitation and may demonstrate the entry and exit points of the intimal dissection and may thus contribute to surgical decisions on the most appropriate operation. It has been our policy not to perform coronary arteriography in patients with proven dissection (although we usually do perform this investigation if aortography is entirely normal and myocardial ischaemia is being considered as an alternative diagnosis) because we are unaware of any evidence that additional coronary bypass grafting at the time of surgery offers any prognostic or symptomatic advantage.

When CT scanning was available (19831987) the clinical outcome in four patients who had only one, investigation (aortography or CT scanning but not both) was believed to require further comment. One patient had negative aortography and died two years later of a myocardial infarct. Necropsy was not performed but there was no clinical suspicion of dissection as a contributory cause of death. Three patients died some time after negative CT scans without subsequent necropsy and we cannot be certain that there was no evidence of previous aortic dissection. One of these patients died five years later; however, the other two died aged 72 and 79 years at 15 and 30 months after investigation, and in none of these three patients was there clinical suspicion of aortic dissection as a contributory cause of death.

The group of patients who were of particular interest were those 16 who had both CT scanning and aortography because there was considerable clinical evidence in the presence of a negative first investigation or because the first investigation had provided insufficient information for management decisions. In 10 the findings were concordant (eight had negative results with both investigations) but in six they were discordant. In this discordant group three patients had negative CT scans as the first investigation but were shown on aortography to have type A dissection; the aortographic findings were confirmed at surgery in all three. The other three patients in the discordant group had negative aortograms first but on subsequent CT scanning were shown to have type $B$ dissection. All these patients are alive so as yet there is no confirmatory necropsy data but all had unequivocal CT appearances strongly suggesting falsely negative aortography.

So of the 62 aortograms performed on patients being admitted for investigation of suspected acute thoracic aortic dissection in the 10 years $1978-1987$ at least four $(6.4 \%)$ were falsely negative. All of these missed type B dissections. Of all the CT scans performed in the years $1982-1987(n=48)$ three $(6 \cdot 2 \%)$ were false negatives. All of these missed type A 
dissections. Because three patients were lost to follow up and eight died without necropsy or surgical confirmation of the diagnosis the true frequency of false negatives could be higher.

We found that any patient with clinically suspected acute thoracic aortic dissection should undergo aortography or CT scanning and that if this investigation is negative but the index of clinical suspicion high then the second investigation should always be performed. A negative first investigation with little clinical evidence of dissection should probably be regarded as sufficient to exclude the diagnosis. Whether aortography or CT scanning is performed as the first investigation is to a large extent dependent on individual circumstances such as the availability of each procedure, the experience of the person who will perform and report on whichever investigation is performed, and the restlessness of the patient (which will affect the quality of the CT scan). With CT scanning but not aortography patients with a low likelihood of dissection can be transferred from other hospitals for investigation and, if shown to have a normal scan, transferred back without being admitted. Our experience with patients in whom there is strong clinical evidence of dissection favours aortography as the first investigation because we were most concerned not to miss type A dissections. The promising experience reported with transoesophageal echocardiography in the investigation of suspected aortic dissection may contribute still further to reducing the likelihood of misdiagnosis. ${ }^{14}$
JMM thanks the British Heart Foundation who supported him with a Fellowship during the period that this work was undertaken.

1 Daily PO, Trueblood HW, Stinson EB, Wuerflein RD, Shumway NE. Management of acute aortic dissection. Ann Thorac Surg 1970;10:237-40.

2 Miller DC, Mitchell RC, Oyer PE, Stinson EB, Jamieson SW, Shumway NE. Independent determinants of operative mortality for patients with aortic dissections. operative mortality for patients with
Circulation 1984;70(suppl 3):I153-64.

3 Vecht RJ, Besterman EMM, Bromley LL, Eastcott HHG, Kenyon JR. Acute dissection of the aorta: long term review and management. Lancet 1980;i:110-3.

4 Grossman W. Cardiac catheterisation and angiography. 3rd ed. Philadelphia: Lea and Febiger, 1986.

5 Egan TJ, Neiman HL, Herman RJ, Malave SR, Sanders JH. Computed tomography in the diagnosis of aortic aneurysm dissection or traumatic injury. Radiology 1980;136:141-6.

6 Thorsen MK, San Dretto MA, Lawson TL, Foley WD, Smith DF, Berland LL. Dissecting aortic aneurysms: accuracy of computed tomographic diagnosis. Radiology 1983;148:773-7.

7 Neumann CH, Guthaner DF, Wong DWH. Aortic dissection: CT and angiographic comparisons. Digitale Bilddiagn 1984:4:14-7.

8 Oudkerk M, Overbosch E, Dee P. CT recognition of acute udkerk M, Overbosch E, Dee P. CT recog
aortic dissection. AJR 1983;141:671-6.

9 Vasile N, Mathieu D, Keita K, Lellouche D, Bloch G, Cachera JP. Computed tomography of thoracic aortic dissection: accuracy and pitfalls. J Comput Assist Tomogr 1986;10:211-5.

10 Eagle KA, Quertermous T, Kritzer GA, et al. Spectrum of conditions initially suggesting acute aortic dissection but with negative aortograms. Am J Cardiol 1986;57:322-6.

11 Parienty RA, Couffinal JC, Wellers M, Farge C, Pradel J, Dologa $M$. Computed tomography versus aortography in diagnosis of aortic dissection. Cardiovasc Intervent Radiol 1982;5:285-91.

12 Singh H, Fitzgerald E, Ruttley MST. Computed tomography: the investigation of choice for aortic dissection? $\mathrm{Br}$ Heart $J 1986 ; 56: 171-5$.

13 Danza FM, Fusco A, Falappa P. The role of computed tomography in the evaluation of dissecting aneurysms. tomography in the evaluatior
Radiology $1984 ; 152: 827-9$.

14 Erbel R, Engberding R, Daniel W, Roelandt J, Visser C, Rennollet H, and the European Cooperative Study Group for Echocardiography. Echocardiograhy in diagnosis of aortic dissection. Lancet 1989;i:457-66. 